\title{
Quality and quantity of sample size is crucial in clinical studies to exclude association: antimicrobial exposure and the risk of delirium in critically ill patients
}

\author{
Rashid Nadeem * ${ }^{*}$, Zainab Ameer Obeida, Sahish Kamat and Ahmed Nazir Elsousi
}

Keywords: Delirium, Cefepime, Antibiotics

To the Editor:

We read with great interest the article published in a recent issue of Critical Care by Grahl et al. [1]. The authors illustrated that there is no association between delirium and cefepime, penicillin, carbapenems, fluoroquinolones, or macrolides.

We would like to point out following concerns about this study.

We believe sample was not representative of general population and sample size was not powered enough to draw these conclusions. Study sample does not include all consecutive subjects from a time frame; a large portion of subjects 96 records (18\%) were excluded because medication data was not available. Intention to include analysis might change results significantly. Authors did not mention if excluded patients' profile was similar to included patients' profile. Delirium was documented in $318(76 \%)$, which is significantly more than expected from a typical ICU which suggests that sample may not be representative of general population. Sample predominantly comprises of Caucasian population (88\%) so results may not be applicable to African American population.

This study found no association between delirium and cefipime. Although the analysis is performed for cefipime as individual drug, actual number of patients treated with cefipime was not provided; the key

\footnotetext{
* Correspondence: Nadeem.dr@gmail.com

Dubai Hospital, P O Box 7272, Dubai, United Arab Emirates
}

component to determine this association. Most likely no association was found as the number was inadequate. This is a common phenomenon; a negative study because of small sample size. Had they analyzed all patients on all cephalosporins including cefepime as one group, they may find association. Conversely they analyzed all other antibiotics (vancomycin, antifungal, antiviral and others) as one group and found them to be associated with delirium. Had they analyzed these antibiotics individually (like cefepime) these antibiotics will also not be associated with delirium as well (sampling error). We believe sample size for patients with cefipime may not be enough to exclude its association with delirium. Moreover median days of use of cefipime was 4.5 days in this study which suggest that physicians might have stopped the drug because of delirium as it is known that delirious effect from cefipime manifest after about 4 days of utilization. It will be interesting if data is available regarding how many patients were on cefipime and how many of them stopped cefepime because of delirium.

Sample also exclude patients with any neurologic disorder, yet $56 \%$ were comatose, and analysis showed no association of delirium with sedatives or opiates. Again it only suggests that sample is not large enough to answer these questions. We have to ask ourselves. Was study powered enough to exclude cefipime as associated factor for delirium?

We would also like to express clearly that previously published data which associate cefipime with delirium is also small, heterogeneous and insufficient and mainly comprise of case reports, case series and meta-analysis 
$[2,3]$. To our knowledge, there is no randomized, prospective trial till date, therefore we believe this question remained unanswered until we have a well design study that is powered enough to answer this important clinical question. Clinicians are advised to exercise their best clinical judgement.

\section{Authors' response}

Jessica J. Grahl, Joanna L. Stollings and Mayur B. Patel

We read with interest the comments by Nadeem et al. regarding the results of a nested cohort study from the BRAIN-ICU Study evaluating the association between antimicrobial class exposure in critically ill patients and the risk of delirium $[4,5]$. After multiple covariate adjustment, only first- to third-generation cephalosporins were associated with delirium.

We agree that the sample size in this study [1] was small and an adequately powered study may provide different findings. However, we believe our cohort was truly reflective of the general ICU population. Delirium occurred in 308 (74\%) of patients in this cohort, which was appropriate for the study time frame (March 2007-May 2010). Delirium recognition and prevention strategies have improved since guideline publications and the ICU Liberation ABCDEF Bundle implementation [6,7].

Cefepime was utilized in 64 (15\%) of the patients that received antimicrobial therapy. This information is listed in supplementary data (Table S1) [4]. We conducted an unpublished statistical analysis looking at beta-lactams as a class and found a statistically significant difference, which is why sub-class analysis was conducted. In order to prevent statistical model overfitting, it was necessary to include a class of "other antimicrobials", as opposed to individualized therapy and covariate adjustments for these multitude of antibiotics without a strong past scientific association with delirium. Although our approach is imperfect, when studying cefepime, all other past studies lack adjustment for competing classes of antibiotics.

It is unlikely that providers would have discontinued therapy due to the incidence of delirium alone. At the time this study was conducted, there was no literature identifying an association between cefepime and delirium based on CAM-ICU monitoring. Rather, we credit the median duration of cefepime of only 4.5 days to twenty-first century antimicrobial stewardship.

We also excluded patients with severe neurological disease, which is common practice in many studies evaluating an association between pharmacotherapy and delirium $[5,8]$ We agree the findings may not be extrapolatable to this patient population. We did not identify an association with use of analgesics and sedatives in the ICU in our proportional odds model. This is most likely because the covariates were binary outcomes measured on ICU admission.
The authors agree with Nadeem et al. that the previously published data associating cefepime with delirium are small, heterogenous, and mostly case reports and series. The current study is the first to date that sought to find an association between antimicrobial therapy and delirium using the CAM-ICU assessment. We agree that future adequately powered studies are warranted. However, we remain leery of reflexively shifting active antimicrobial strategies simply because of the occurrence of delirium.

\section{Acknowledgements \\ None. \\ Funding \\ None. \\ Availability of data and materials \\ Not applicable.}

Authors' contributions

All authors contributed equally. All authors read and approved the final manuscript.

Authors' information

Submitted in title page.

Ethics approval and consent to participate

Not applicable.

Consent for publication

Not applicable.

Competing interests

The authors declare that they have no competing interests.

\section{Publisher's Note}

Springer Nature remains neutral with regard to jurisdictional claims in published maps and institutional affiliations.

Received: 14 February 2019 Accepted: 28 February 2019

Published online: 29 April 2019

References

1. Grahl JJ, Stollings JL, Rakhit S, Person AK, Wang L, Thompson JL, Pandharipande PP, Ely EW, Patel MB. Antimicrobial exposure and the risk of delirium in critically ill patients. Crit Care. 2018;22(1):337.

2. Appa AA, Jain R, Rakita RM, Hakimian S, Pottinger PS. Characterizing cefepime neurotoxicity: a systematic review. Open Forum Infect Dis. 2017; 4(4):ofx170 US: Oxford University Press.

3. Payne LE, Gagnon DJ, Riker RR, Seder DB, Glisic EK, Morris JG, Fraser GL. Cefepime-induced neurotoxicity: A systematic review. Crit Care. 2017;21(1): 276.

4. Grahl JJ, Stollings JL, Rakhit S, et al. Antimicrobial exposure and the risk of delirium in critically ill patients. Crit Care Lond Engl. 2018;22(1):337. https:// doi.org/10.1186/s13054-018-2262-z. 
5. Pandharipande PP, Pun BT, Herr DL, et al. Effect of sedation with dexmedetomidine vs lorazepam on acute brain dysfunction in mechanically ventilated patients: The MENDS randomized controlled trial. JAMA. 2007; 298(22):2644-53. https://doi.org/10.1001/jama.298.22.2644.

6. Barr J, Fraser GL, Puntillo K, et al. Clinical practice guidelines for the management of pain, agitation, and delirium in adult patients in the intensive care unit. Crit Care Med. 2013;41(1):263-306. https://doi.org/10 1097/CCM.0b013e3182783b72.

7. Marra A, Ely EW, Pandharipande PP, Patel MB. The ABCDEF bundle in critical care. Crit Care Clin. 2017;33(2):225-43. https://doi.org/10.1016/j.ccc.2016.12. 005.

8. Jakob SM, Ruokonen E, Grounds RM, et al. Dexmedetomidine vs midazolam or propofol for sedation during prolonged mechanical ventilation: Two randomized controlled trials. JAMA. 2012;307(11):1151-60. https://doi.org/10. 1001/jama.2012.304

Ready to submit your research? Choose BMC and benefit from:

- fast, convenient online submission

- thorough peer review by experienced researchers in your field

- rapid publication on acceptance

- support for research data, including large and complex data types

- gold Open Access which fosters wider collaboration and increased citations

- maximum visibility for your research: over $100 \mathrm{M}$ website views per year

At BMC, research is always in progress.

Learn more biomedcentral.com/submissions 